\title{
SAÚDE MENTAL E O TRABALHO DE CAMINHONEIROS DE CARGAS NAS RODOVIAS
}

DOI: 10.22289/2446-922X.V2S1A3

\author{
Beatriz Ferreira Gomes ${ }^{1}$ \\ Constance Rezende Bonvicini ${ }^{2}$
}

\section{INTRODUÇÃO}

Os transtornos mentais são determinados por diversos fatores, incluindo o efeito crônico de uma vida mental sem saída, mantido por uma precária organização do trabalho, favorecendo o adoecimento mental do trabalhador. ${ }^{(1)}$

Assim, interessa-se em debater sobre a saúde e como os trabalhadores vivem o seu cotidiano. O objetivo do estudo é relacionar saúde mental dos caminhoneiros e as condições de trabalho, frente ao estresse laboral proveniente do trânsito e das estradas, apontando para o papel do psicólogo do trabalho. A rotina diária de trabalho associada às condições desfavoráveis que se relacionam, são indícios de comprometimento da saúde, acidentes e violência que estão ligadas ao trânsito. ${ }^{(2,3)}$

\section{MÉTODOS}

Este estudo foi realizado como forma de trabalho de conclusão de curso, por meio de uma revisão da literatura, sendo de caráter qualitativo e descritivo. Para realização deste trabalho foram utilizados como materiais e fontes de pesquisa: livros e artigos obtidos na base de dados da Scielo e Lilacs, e teses e dissertações disponíveis no banco de dados da biblioteca virtual das universidades.

Foram usados preferencialmente artigos publicados no idioma português no período de 2000 a 2016, bem como obras clássicas. As palavras-chave utilizadas na busca de materiais foram: Saúde Mental. Estresse no trabalho. Trabalho de caminhoneiros.

\footnotetext{
${ }^{1}$ Graduanda em Psicologia pela Faculdade Patos de Minas (FPM).

${ }^{2}$ Mestre em Administração pela Faculdade Novos Horizontes. Docente do Departamento de Graduação em Psicologia da Faculdade Patos de Minas (FPM). E-mail de contato:

constancebonvicini@yahoo.com.br.
} 


\section{RESULTADOS E DISCUSSÃO:}

As condições de trabalho na atualidade estão cada vez mais estressantes e insensíveis às condições humanas, pois há cobranças para se obter uma maior produtividade e a melhor qualidade, seja nos produtos ou serviços. Diante de tais mudanças envolvendo inclusive a tecnologia, as formas produtivas, os trabalhadores são afetados diretamente. As mudanças de rotina de trabalho contribuem para um grande aumento ou até mesmo o aparecimento de doenças relacionadas ao trabalho. ${ }^{(4)}$

Os trabalhadores motoristas de cargas em rodovias acabam por desencadear transtornos mentais, que estão descritos entre os problemas de saúde relacionados ao trabalho, podendo afetar qualquer pessoa, setor ou organização. Visto como um problema de saúde pública na sociedade moderna, se trata de disfunções graves para o trabalhador e a sociedade em geral.

A realidade dos motoristas caminhoneiros de cargas mostra um contexto precário em termos de condições de trabalho, assim, estão mais predispostos a fatores desencadeantes de transtornos psíquicos. Seu trabalho é permeado por pressões do dia a dia nas estradas, violência do trânsito, insegurança, medo, metas a serem cumpridas e longas jornadas de trabalho. Inclui-se no contexto, o fato de estarem quase sempre sobre efeitos de drogas para driblar o sono e o cansaço, a distância da família e a falta de convívio social ajudam no aparecimento de doenças relacionadas ao trabalho e aumento das estatísticas de acidentes de trânsito. ${ }^{(5)}$

Perante as condições precárias do trabalhador, especificando-se o caminhoneiro nesse artigo, cabe ao psicólogo no exercício de sua profissão ligada diretamente ao labor, trabalhar as questões subjetivas de cada um. O psicólogo deve estimular o trabalhador a desenvolver suas capacidades e potenciais, elucidando-os sobre as condições que lhes são oferecidas e sobre a organização de seu trabalho. Deve buscar uma formação mais focada no ser humano, por conseguinte, um olhar mais voltado sobre o ser humano, nas relações com suas atividades laborais na forma que foi inserido no processo: condições, organização e a divisão do trabalho. ${ }^{(6)}$

Atentando para a qualidade de vida, o psicólogo possibilita o indivíduo a ter a percepção sobre sua posição na vida, no contexto de sua cultura e dos valores em relação aos seus objetivos. Analisa-se inclusive o grau de satisfação que ele encontra na vida pessoal, familiar, social e profissional, entendendo que a qualidade de vida não depende do que the é exigido, mas também da percepção que cada indivíduo tem em relação as suas expectativas pessoais e profissionais. ${ }^{(7)}$ 


\section{CONSIDERAÇÕES}

O trabalho sendo a atividade que mais exige que o homem esteja bem com sua integridade física e mental deve ser pensado na relação trabalho e saúde mental. Destaca-se que o indivíduo deve estar satisfeito com o seu trabalho, dessa forma, possibilitado a manter o equilíbrio entre a vida laboral e pessoal, consequentemente apresentando um funcionamento psíquico saudável.

Diante do estudo realizado para elaboração desse trabalho, percebe-se um número grande de pesquisas nessa área, tratam especificamente sobre a saúde mental dos trabalhadores em geral, especificamente sobre os condutores de caminhões que realizam o transporte de cargas, se faz necessário que se façam pesquisas mais recentes. Podendo-se utilizar novas ferramentas para que seja bem trabalhado as questões psíquicas dos trabalhadores em que as condições de trabalho favorecem o desencadeamento de transtornos mentais.

\section{REFERENCIAS}

1. Dejours JC. A loucura do trabalho. São Paulo: Cortez; 1992. 122 p.

2. Sinagawa DM. Uso de substâncias psicoativas por motoristas profissionais no estado de São Paulo [dissertação]. São Paulo: Universidade de São Paulo (USP); 2015.

3. Bonvicini CR, Silva JC. Violência e promoção da saúde. Rev Psicol e Saúde em Debate, 2015;1(1):78-88.

4. Correa AS, Menezes JRM. Estresse e trabalho [monografia]. Campo Grande: Sociedade Universitária Estácio de Sã; 2002.

5. Girotto E. Características do trabalho, consumo de substâncias psicoativas e acidentes de trânsito entre motoristas de caminhão [dissertação]. Londrina: Universidade Estadual de Londrina (UEL); 2014.

6. Souza WF. Transtornos mentais e comportamentais relacionados ao trabalho: o que a psicologia tem a dizer e a contribuir para a saúde de quem trabalha? Fractal Rev Psicol, 2013;25(1):99-108. 
7. Diniz F, Freitas VL, Hermones R, Neves MP. Promoção de saúde e qualidade de vida: uma revisão bibliográfica. Rev Acta Cient, 2010;2(2):53-63. 